\title{
Análisis de parámetros del cultivo y procesos de la transformación del café
}

\section{Analysis of crop parameters and coffee transformation processes}

\author{
LAGUNES-PAREDES, Yolanda*†, RAMÍREZ-ROMAN, Adolfo, SUAREZ-ALVAREZ, Ángel y \\ OLIVARES-SILVA, Teresita de Jesús
}

Universidad Veracruzana

ID $1^{\text {er }}$ Autor: Yolanda, Lagunes-Paredes / ORC ID: 0000-0003-0328-3846, CVU CONACYT ID: 1013775

ID $1^{\text {er }}$ Coautor: Adolfo, Ramirez-Roman / ORC ID: 0000-0002-3820-8582, CVU CONACYT ID: 244749

ID $2^{\text {do }}$ Coautor: Angel, Suarez-Alvarez / ORC ID: 0000-0002-0726-9630, CVU CONACYT ID: 946964

ID $3^{\text {er }}$ Coautor: Teresita de Jesús, Olivares-Silva / ORC ID: 0000-0002-9062-2385, CVU CONACYT ID: 1013768

DOI: $10.35429 / J B E B .2019 .7 .3 .18 .30$

Recibido 16 de Enero, 2019; Aceptado 30 Marzo, 2019

\section{Resumen}

Existen factores ambientales que influyen en la "calidad" del café: suelo, altitud, agua, sombreado, temperatura, vientos, precipitación. Este trabajo de investigación se analizó factores físicos y químicos: altitud, humedad del ambiente y suelo, y $\mathrm{pH}$ del suelo, en tres diferentes regiones tales como Córdoba, Coatepec y Xico. Estas presentaron temperaturas y humedades variables, el pH del suelo fue más ácido en regiones altas y húmedas y también fueron variables en los diferentes muestreos, por los cambios de temperatura. Se analizó el porcentaje de humedad del grano de café, por ser una condición importante para considerar al café apto para el siguiente proceso del tostado. Finalmente se realizó el proceso de tostado del café de cada región; usando un término claro, medio y oscuro. Posteriormente se analizó el pH de cada muestra de café molido en agua caliente, sin embargo, la acidez no se refiere al nivel del grado de acidez del café, no debe confundirse con el carácter de acidez. Proceso meramente químico, Una acidez alta es descrita como brillante, mientras que un café de baja acidez puede ser descrito como suave, y el bajo, considerado poco interesante. Una falta total de acidez también puede resultar en un café plano.

Acidez, Calidad, Factores ambientales, Café

\begin{abstract}
There are environmental factors that influence the "quality" of coffee: soil, altitude, water, shading, temperature, winds, precipitation. This research paper analyzed physical and chemical factors: altitude, humidity of the environment and soil, and soil $\mathrm{pH}$, in three different regions such as Córdoba, Coatepec and Xico. These temperatures and humidity varied, the $\mathrm{pH}$ of the soil was more acidic in high and humid regions and they were also variable in the different samples, due to temperature changes. The percentage of coffee bean moisture was analyzed, as it is an important condition to consider coffee suitable for the next roasting process. Finally, the coffee roasting process of each region was carried out; using a light, medium and dark term. Subsequently, the $\mathrm{pH}$ of each sample of coffee ground in hot water is analyzed, however, the acidity does not refer to the level of acidity of the coffee, it should not be confused with the character of acidity. Purely chemical process, A high acidity is described as bright, while a coffee with low acidity can be described as mild, and the low, considered uninteresting. A total lack of acidity can also result in a flat coffee.
\end{abstract}

Acidity, Quality, Environmental factors, coffee

Citación: LAGUNES-PAREDES, Yolanda, RAMÍREZ-ROMAN, Adolfo, SUAREZ-ALVAREZ, Ángel y OLIVARESSILVA, Teresita de Jesús. Análisis de parámetros del cultivo y procesos de la transformación del café. Revista de Ingeniería Biomédica y Biotecnología. 2019. 3-7: 18-30

\footnotetext{
* Correspondencia del Autor (ylagunes@uv.mx)

$\dagger$ Investigador contribuyendo como primer autor
} 


\section{Introducción}

El rubro café es en la actualidad el segundo producto comercial más importante del mundo después del petróleo, siendo sus granos considerados como el primer "commodity" internacional. $\mathrm{La}$ producción de café se concentra en 52 países, en su mayoría distribuidos principalmente en las regiones ecuatoriales con condiciones agroclimatológicas favorables para su desarrollo

El clima limita el cultivo del café a la franja tropical, mientras que la altura incide y condiciona la apreciada acidez de un buen café, entre otros aspectos. Ambos factores son determinantes y únicamente en los casos donde se produce una combinación perfecta de los dos parámetros, además, de una buena intervención humana a modo de prácticas agrícolas y cultivo y proceso de café, se obtiene como resultado una buena materia prima, que tostadores y baristas deberán acabar de mimar para conseguir la taza de café perfecta.

Bajo las consideraciones aquí planteadas se puede definir también que la calidad del café se ve afectada por numerosos factores, entre ellos: la variedad, suelo, clima, prácticas de producción, cosecha, postcosecha y el beneficio agroindustrial. Como objeto de estudio de este trabajo se analizaron algunos de los parámetros que pueden llegar a afectar al cultivo del café, y por ende como influyen en el grado de acidez de este. Como todas las plantas, el café necesita de condiciones ambientales especiales para su producción, y todas ellas tienen importancia; el $\mathrm{pH}$ del suelo, la temperatura, la altura, los vientos, las lluvias, la humedad entre otros.

Dado la importancia que tiene la acidez del café, se analizan parámetros ambientales, $\mathrm{pH}$, altura, humedad, temperatura y la cinética de secado del grano de café, se tomarán muestras en tres diferentes lugares del estado de Veracruz: Córdoba, Coatepec y Xico. Con el objetivo de poder determinar la influencia de los factores antes mencionados en el grado de acidez del café, por lo que también se lleva a cabo el estudio del proceso de tostado de cada una de las muestras. Cabe recalcar que esta investigación recoge análisis de los lugares mencionados para hacer estudios, los cuales no se han llevado a cabo en estas zonas, ni tampoco una comparación entre estas, brindando un panorama más amplio para futuros trabajos sobre el procesamiento de café.

\section{Justificación}

Los cafetales mexicanos son grandes productores de oxígeno. El café en el país es producido por cerca de 300 mil productores, agrupados en 16 organizaciones estatales de productores. México produce café de excelente calidad ya que existen las condiciones ideales para el cultivo. Esta investigación recoge análisis de La relevancia del tema es debido a que México cuenta con una enorme tradición en el cultivo del café, con una experiencia y conocimiento de más de 200 años. La calidad del café es el resultado de un conjunto de procesos que permiten la expresión, desarrollo y conservación de las características fisicoquímicas propias del café hasta el momento de su transformación y consumo. En sí, la calidad del café es el conjunto de cualidades sensoriales que tiene el café. La presente investigación incursiona en los factores que influyen en la acidez del café, así como también su calidad, es por esta razón la importancia de analizar e identificar como los factores del medio ambiente influyen en la acidez y la calidad del grano de café, no sin antes considerar que el grado de acidez es relativo al gusto del catador, sin embargo uno de las principales consideraciones en este trabajo es presentar la influencia de algunos parámetros durante proceso de cultivo, y del tostado del grano en tres productores del estado de Veracruz, los cuales no se han llevado a cabo en estas zonas, ni tampoco una comparación entre estas.

\section{Objetivo}

Analizar los parámetros físicos y químicos del cultivo del café, y del proceso de transformación del grano, para identificar cómo estos influyen en su grado de acidez.

\section{Hipótesis}

Algunos factores químicos y físicos del suelo de cultivo, tales como $\mathrm{pH}$, humedad, temperatura y altura afectan directamente en el grado de acidez del café.

\section{El café}

Se conocen como café los granos obtenidos de unas plantas perennes tropicales (cafetos), morfológicamente muy variables, los cuales, tostados y molidos, son usados principalmente para preparar y tomar como una infusión.

LAGUNES-PAREDES, Yolanda, RAMÍREZ-ROMAN, Adolfo, SUAREZ-ALVAREZ, Ángel y OLIVARES-SILVA, Teresita de Jesús. Análisis de parámetros del cultivo y procesos de la transformación del café. Revista de Ingeniería Biomédica y Biotecnología. 2019 
El café es una de las bebidas más populares en el mundo y posiblemente la más consumida. El género pertenece a la familia de las Rubiáceas (Rubiaceae), que tiene alrededor de 500 géneros y más de 6000 especies, la mayoría árboles y arbustos. Son principalmente de origen tropical, y de una amplia distribución, a ella pertenecen plantas medicinales como la ipecacuana (Psichoria ipecacuanha), o la Cinchona spp., de la cual se extrae la quinina. Taxonómicamente, todas estas plantas se clasifican como del género Coffea, y se caracterizan por una hendidura en la parte central de la semilla. Se encuentran desde pequeños arbustos hasta árboles de más de $10 \mathrm{~m}$.; sus hojas, que son simples, opuestas y con estípulas, varían tanto en tamaño como en textura; sus flores son completas (en la misma flor se encuentran todos los órganos) blancas y tubulares; y los frutos, son unas drupas de diferentes formas, colores y tamaños, dentro de las cuales se encuentran las semillas, normalmente dos por fruto.

\section{Origen del café}

El consumo de café se originó en Etiopía alrededor del siglo IX y posteriormente, en el siglo XV se difundió de los monasterios sufíes yemeníes al resto del Medio Oriente y el norte de África. Para el siglo XVIII la bebida ya era muy popular en Europa siendo los originarios de ese continente quienes comenzaron a introducir el cultivo en muchas de sus colonias tropicales a fin de atender la creciente demanda (AMECAFE, 2012).

\section{Consumo de café}

El consumo de café se inició en Etiopía con la especie C. arábica. Al comienzo se prepararon infusiones con las hojas y frutos, mientras que los granos fueron, y aún lo son en parte del África, mascados. Es probable que las cerezas mezcladas en las infusiones o arrojadas al fuego les permitieran sentir un mayor aroma y un mejor sabor e iniciar su consumo moderno. Fueron los Yemenitas quienes lo popularizaron y respecto de los comienzos de su uso se han difundido numerosas leyendas, de las cuales la más difundida es la que cuenta que un joven pastor llamado Kaldi. Este pastor un día notó en su rebaño, un comportamiento extraño: sus cabras saltaban y corrían contagiadas de una euforia desbordante.
Al ver esta extraña conducta, la curiosidad llevó a Kaldi a observar que los animales cambiaban su comportamiento después de comer las hojas y los frutos de un arbusto que producía pequeñas cerezas rojas. Dice la fábula que el pequeño pastor probó los frutos y al poco tiempo se sintió poseído por una extraña alegría que los impulsaba a cantar y danzar. Kaldi llevó algunas ramas y frutos al superior de un convento ubicado en las cercanías de su campo de pastoreo. Contó al abad lo sucedido con su rebaño.

El superior del convento accidentalmente echó los frutos al fuego y fue la primera vez que el hombre experimentó el aroma del café. Las más recientes versiones de la leyenda indican que el pastor era oriundo de Etiopía, en tanto que las más antiguas sugieren que Kaldi estaba pastoreando en las montañas de la Península Arábica. Es por ello por lo que hasta mediados del siglo pasado se consideró que el café era originario de Arabia, lo que lo hace consistente con otras de las leyendas más conocidas que explican el origen del consumo de la bebida, como la de Shadhiliya y Omar.

\section{Especies comerciales y su origen}

Coffea canephoraPierre exFroehne tiene una amplia distribución geográfica y se encuentra silvestre en el África, como en Congo, Sudán, Uganda, y el Noroeste de Tanzania y Angola. Aproximadamente, el 35\% del café que se comercializa en el mundo es de esta especie, conocida como Robusta. Las variedades de Robusta, por lo general, tienen órganos pequeños (hojas, frutos, flores y granos) y son conocidas como Conilon, Koulliou o Quillou. arabica L. es actualmente la principal especie del género, y constituye más del $60 \%$ del café que se comercializa en el mercado internacional. Es una especie autógama, es decir, se autopoliniza o autofertiliza. Su centro de origen se encuentra en el Sudeste de Etiopía, el Sur de Sudán y el Norte de Kenya. Es una especie tetraploide (tiene 44 cromosomas), que proviene de formas antiguas de dos especies diploides Coffea eugenioides (22 cromosomas), probablemente como madre, y C. canephora $(22$ cromosomas), como padre. 


\section{Distribución del café en el mundo}

Posterior a su descubrimiento, el cultivo del café se extendió por las regiones ubicadas entre el trópico de Cáncer y el de Capricornio (Figura 1), mientras que sus consumidores estaban principalmente en países del hemisferio norte (Contreras y Hernández-Martínez, 2008). El mayor consumo generó una expansión en su producción. En el siglo XIV, los árabes llevaron la planta a Yemen, donde aparecieron las primeras plantaciones que generaron un gran rédito económico.

El monopolio árabe de la producción de café estuvo basado en la prohibición de exportación de semillas y en el mantenimiento de un cuidadoso secreto sobre las técnicas de cultivo. Como consecuencia de esta estrategia, el puerto yemení de Mocha, sobre el mar rojo, se constituyó en el principal centro de comercio de café hasta el siglo XVII.

La expansión del cultivo del café en diversos continentes la iniciaron los holandeses para no tener que depender de los árabes. Los holandeses lograron acceder a las semillas y fueron quienes desarrollaron los primeros cultivos intensivos en la India y en Ceilán (hoy Sri Lanka) en el siglo XVII, y en Indonesia a fines de ese siglo y comienzos del XVIII.

México produce cafés de excelentes calidades, ya que su topografía, altura, climas y suelos le permiten cultivar y producir variedades clasificadas dentro de las mejores del mundo.

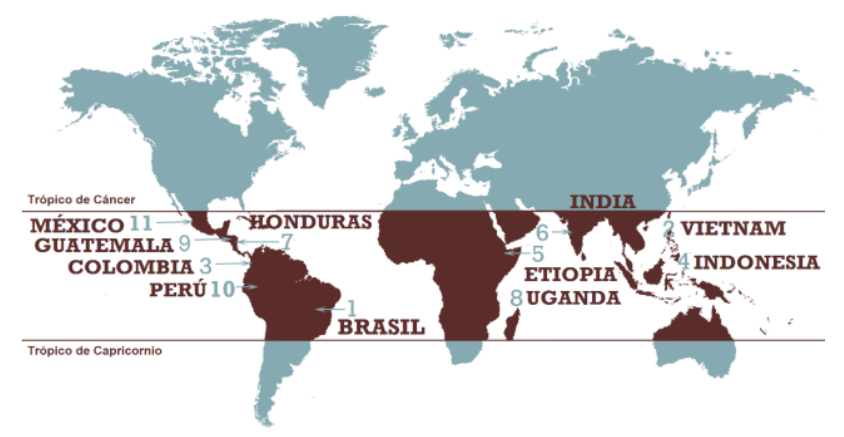

Figura 1. Distribución del cultivo de café en el mundo y principales países productores en 2015

\section{Producción mundial de café}

El café es uno de los productos primarios más valiosos en el comercio mundial, de acuerdo con la Organización Internacional del Café, la producción mundial de este producto fue de alrededor de 143 millones de sacos de $60 \mathrm{~kg}$ en el año 2015. La mayor producción se ubica en América (62\%), Asia (24\%), África (13\%) y Oceanía (1\%). A nivel mundial, México ocupa el onceavo lugar (2\%) después de Brasil, Vietnam, Colombia, Indonesia, entre otros (ICO, 2016; Figura 1 y 2).

PRODUCCIÓN MUNDIAL DE CAFÉ VERDE 2015

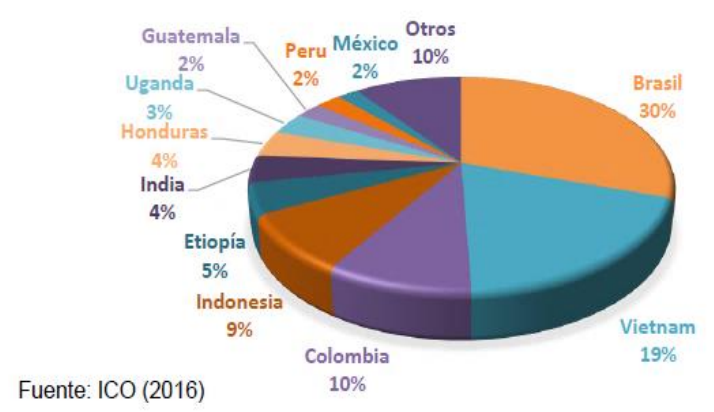

Figura 2 Producción mundial de café verde en 2015

\section{Producción de café en México}

El café se introdujo a México en el año de 1796, $y$ actualmente se ha extendido por cuatro regiones del país: Vertiente del Golfo de México (San Luis Potosí, Querétaro, Hidalgo, Puebla, Veracruz y la parte norte de Oaxaca y Tabasco), Vertiente del Océano Pacífico (Colima, Guerrero, Jalisco, Nayarit y parte de Oaxaca), Región Soconusco (gran parte del estado de Chiapas) y la Región Centro-Norte de Chiapas. Para México, el café representa una actividad estratégica; emplea a más de 500 mil productores, 727 mil hectáreas de 12 entidades federativas y 391 municipio (SAGARPA, 2016).

Desde el punto de vista biológica, las áreas cafetaleras coinciden con las regiones más ricas y diversas en flora y fauna. La cosecha de café en México se realiza principalmente de octubre a marzo. La actividad cafetalera nacional se concentra en los estados de Chiapas, Veracruz, Oaxaca y Puebla. La producción nacional de café cereza en el periodo enero-abril del 2015 fue de 1,026,252 toneladas. En la tabla 1 se muestra la superficie sembrada, la producción por toneladas y el rendimiento de café cereza hasta abril del 2015 (SAGARPA, 2016). 


\begin{tabular}{lccc}
\hline Estado & $\begin{array}{c}\text { Superficie sembradada } \\
\text { (ha) }\end{array}$ & $\begin{array}{c}\text { Producción } \\
\text { (ton) }\end{array}$ & $\begin{array}{c}\text { Rendimiento } \\
\text { (tonha) }\end{array}$ \\
\hline Chiapas & 261,571 & 383,059 & 1.56 \\
Veracruz & 145,373 & 276,054 & 2.03 \\
Oaxaca & 139,819 & 171,320 & 0.7 \\
Puebla & 73,645 & 82,512 & 2.87 \\
Guerero & 47,192 & 45,230 & 1.08 \\
Hidalgo & 24,653 & 31,732 & 1.32 \\
\hline
\end{tabular}

Tabla 1 Superficie sembrada, producción y rendimiento de café cereza en los estados de mayor producción en México

\section{Producción de café en Veracruz}

El estado de Veracruz ocupa el segundo lugar en producción de café en el país, en tanto que las regiones de Córdoba y Coatepec son reconocidas por su calidad en el mercado internacional (Mestries, 2006; ASERCA, 2002). En cuanto a la distribución de la producción de café, Veracruz se encuentra en la zona de alta producción con un 89\% (SAGARPA, 2014; Figura 3).

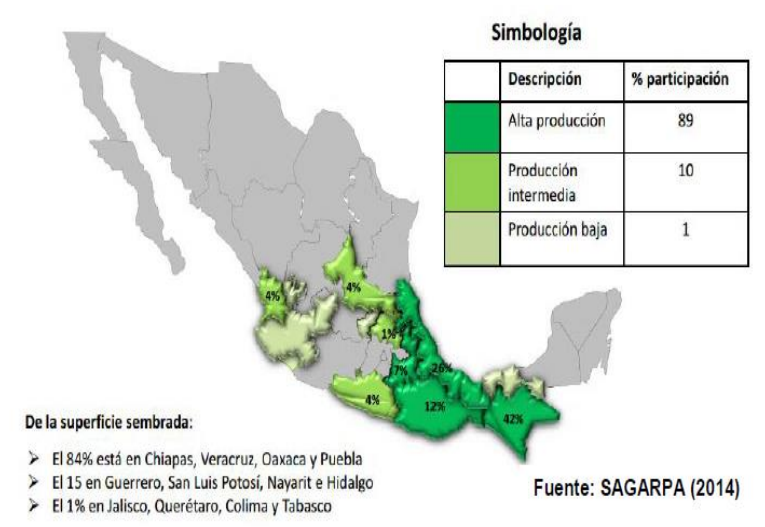

Figura 2 Distribución de la producción de café 2011/12 por estado

\section{Aspectos generales del cultivo del café}

Por las características del cafeto, su producción está acotada por límites geográficos comprendidos por los Trópicos de Cáncer y de Capricornio. A nivel mundial, se cultiva en más de 70 países ubicados en esta franja, destacando de manera importante Brasil, Colombia, Indonesia, India y más recientemente Vietnam (AMECAFE, 2012). Las características que definen básicamente sus cualidades dependen mayoritariamente de sus variedades y de su procedencia (Nuestro Café, s/f).

\section{Condiciones ambientales del cultivo del café}

Como todas las plantas, el café necesita de condiciones ambientales especiales para su producción, a continuación, se describe cada una de ellas y su importancia.

\section{El suelo}

Si bien se considera que los suelos de origen volcánico son los más convenientes para el cultivo de café, lo cierto es que los cafetos se desarrollan bien en otros suelos muy dispares, considerándose los mejores los que tienen un contenido de materia orgánica entre el 8 y el $12 \%$. Los mejores suelos para la producción de café tienen como denominador común, además, un $\mathrm{pH}$ alrededor de 5,5, aunque con una adecuada fertilización, es posible cultivar café en suelo poco ácidos o en neutros con un pH 7,0.

\section{Temperatura}

Las temperaturas elevadas tampoco son buenas para los cafetos. Por encima de los $30^{\circ} \mathrm{C} \mathrm{y}$, sobre todo, si el ambiente es seco, la actividad de la fotosíntesis se reduce, el follaje se marchita y cae, dejando expuestas a las cerezas a la intemperie. El resultado es que buena parte de ellas caen también. Cuando las lluvias vuelven a aparecer, su primer trabajo es reconstruir las hojas, pero no los frutos, con lo cual el árbol, se regenera un poco, pero la cosecha se pierde o casi se pierde. En general, la temperatura ideal para un cafeto es entre 20 y $22^{\circ} \mathrm{C}$, con unas oscilaciones poco marcadas, para plantaciones situadas entre los 600 y los 1600 metros sobre el nivel del mar.

\section{Latitud y altura}

La latitud de la ubicación de los cafetales influye en la cantidad de energía solar recibida por los cafetos debido al ángulo de incidencia de los rayos solares sobre la planta. esta variante, además, determina el horario en el que el arbusto de café recibe la radiación solar. Según estimaciones fiables, cada 100 metros, la temperatura suele descender medio grado y a mayor altura las plantas serán más expuestas a los rayos infrarrojos y ultravioletas del sol. 


\section{El agua}

Cerca del $90 \%$ del peso de un cafeto es agua, sea está en estado líquido como en estado metabólico formado por sus componentes estructurales. El cafeto tiene un buen desarrollo a partir de unas precipitaciones de $1500 \mathrm{~mm}$ anuales con periodos de algunos meses sin o con poca lluvia. El cafeto resiste la sequía, pero no es una planta a prueba de ella. Tiene una recuperación notable después de temporadas de secas, pero como todos los organismos vivos necesita agua para sobrevivir. De hecho, son muy pocos los cafés de zonas pluviales marginales que hayan merecido el rango de los cafés realmente notables y tampoco los de aquellas zonas en las que se producen grandes contrastes entre las estaciones. Para asegurar una buena calidad de la cereza, el agua debe estar repartida a lo largo del año, no compensando lluvias copiosas con sequias prolongadas

\section{Vientos}

Los vientos también son importantes en la producción del café, porque si los vientos superan los $30 \mathrm{Km}$. /h se produce un daño en la planta con la caída de hojas, rotura de flores y frutos y deshidratación de las yemas.

\section{Humedad}

La humedad es también muy importante y va de la mano de las precipitaciones. Si la humedad relativa es mayor a $90.0 \%$ hay riesgo de que la planta se enferme con hongos.

\section{Procesamiento del café en México}

Una vez cortado el fruto del café, es sometido a un proceso o beneficiado por una de las dos vías existentes: el método húmedo y el método seco. El primero, también llamado café lavado es el más costoso y complejo. Este método emplea a los cafés arábicas de alta calidad, con la finalidad de conservar todas sus propiedades, por tal razón son los cafés más caros o mejor pagados, todo este proceso trae como consecuencias la generación de residuos como pulpa y aguas mieles, los cuales si no se manejan adecuadamente generan dificultades al ambiente.
De los dos procedimientos de trasformación primaria del café: a) "la vía húmeda" incluye las etapas de beneficiado húmedo y seco para la obtención de café pergamino y verde $u$ oro lavado o suave; $b$ ) en el caso de "la vía seca", se obtiene el café bola o capulín, que da lugar al café oro natural. Hacia el año 2002, existían cerca de 2 mil unidades de beneficio húmedo y más de 440 unidades para el beneficio seco. En Chiapas y Veracruz se encuentran el $70.0 \%$ de beneficios húmedos y el $53.0 \%$ de beneficios secos.

\section{Procesamiento del café en el estado de Veracruz}

Hablar del café nacional involucra obligadamente a la cafeticultura veracruzana, debido a que el aromático ingresó al país por este estado y en sus zonas montañosas encontró las características idóneas para prosperar. La región cafetalera de Veracruz se encuentra distribuida en 842 comunidades y 82 municipios en donde habitan cerca de 86 mil productores, algunos son habitantes indígenas que pertenecen a las etnias náhuatl, totonaca y popoluca.

En Veracruz se distinguen tres tipos de productores de café: pequeños productores $\mathrm{o}$ minifundistas, productores agrícolas $\mathrm{y}$ productores secundarios, para quienes la siembra de este producto no representa su actividad principal. El 95.5 por ciento de las fincas cafetaleras del estado tienen una superficie menor a las tres hectáreas, en muchas de las cuales sus dueños manejan el policultivo. Varios de estos productores siembran dentro de sus cafetales productos prehispánicos como el cacao y la vainilla, lo que da un valor agregado a sus cultivos.

\section{Beneficio húmedo}

El país se ha caracterizado por la exportación de cafés suaves o lavados, por lo que cerca del $90.0 \%$ de la producción se beneficia a través de la vía húmeda.

1. Pizca de cereza de café; cuando el café alcanza su maduración, es cortado o pizcado a mano, para ser llevado a su proceso de beneficio húmedo.

2. Sifón; las cerezas de café recolectadas se vacían en un estanque llamado sifón: las que alcanzaron su madurez y no tienen defectos se hunden y las demás quedan flotando.

LAGUNES-PAREDES, Yolanda, RAMÍREZ-ROMAN, Adolfo, SUAREZ-ALVAREZ, Ángel y OLIVARES-SILVA, Teresita de Jesús. Análisis de parámetros del cultivo y procesos de la transformación del café. Revista de Ingeniería Biomédica y Biotecnología. 2019 
3. Despulpado. Una vez clasificadas, pasan con agua a través de una despulpadora, que, por fricción, separa la pulpa de las semillas. La pulpa se usa como fertilizante orgánico y las semillas de café caen en el estanque de fermentación.

4. Fermentado; las semillas ya despulpadas se fermentan 24 horas, tiempo en que la semilla suelta el mucílago y las mieles adheridos. Cualquier error de tiempo en esta fase provocaría un gran daño a la calidad del café.

5. Lavado; después del proceso de fermentado, se lavan con agua pura para quitar los residuos y separar cáscaras y cerezos, quedando el café pergamino completamente limpio para escurrirse. El secado puede efectuarse en una secadora mecánica o en patios de asoleo. De esto depende la obtención de una coloración uniforme del grano verde, que deberá mantener $12 \%$ de humedad. De este proceso se obtiene: café pergamino y café segundas de pergamino.

\section{Beneficio seco}

Las cerezas recolectadas se clasifican y se limpian. Se desestiman todas las que no estén en el punto de maduración optimo o dañadas.

En la fase del secado las cerezas se extienden al sol en esteras alzadas sobre caballetes o en patios específicos de cemento o ladrillo.

La mano humana juega un papel clave, ya que se debe voltear el caf4e de manera habitual para que el secado sea homogéneo, esto puede durar hasta cuatro semanas ya que el nivel de humedad de las cerezas debe ser, como mucho, del $12.5 \%$.

\section{Tostado del café}

La torrefacción consiste en tostar el café por medio del calor, las técnicas usadas tratan de que en este proceso se realice el mínimo deterioro, tanto del aroma como en el sabor, así como en el cuerpo del café. El café al tostarse pierde peso y se debe en parte a la pérdida de humedad y a la descomposición y volatilidad de varios componentes químicos de los cuales está constituido el grano.
Durante el proceso de torrefacción ocurren transformaciones importantes debido a las temperaturas alcanzadas progresivamente, al llegar a $100^{\circ} \mathrm{C}$ se pierde humedad y su color cambia lentamente a un color amarillo intenso, entre los 150 y $180^{\circ} \mathrm{C}$ los granos adquieren tonalidades como el pardo claro al marrón, y es cuando los granos se hinchan y de las ranuras brotan aceites volátiles, un aroma bastante agradable emana de los granos que justamente empiezan a crepitar, en este punto los granos han desarrollado el color marrón oscuro. Cuando la temperatura alcanza los $230^{\circ} \mathrm{C}$, es el momento justo de retirar el café del tostador. Una vez logrado el punto de tostado deseado el café pasa de la tostadora a un plato de enfriamiento, que, mediante un muy eficiente aspirador de aire, logra bajarle al grano niveles muy cercanos a la temperatura ambiente para que luego se almacene en silos, con el fin de que termine de refrescar. Concluido este proceso queda en espera de ser empacado directamente en grano, o ser enviado a los molinos. Durante este proceso el tostador debe mantener una constante supervisión del grano que no tolera ningún tipo de error ni distracción. Con el tostado resaltan las cualidades del café, por eso se debe tener mucho cuidado antes, durante y después de tostarlo. Existen varios tipos o grados de tostado que el mercado pide según el gusto de los consumidores de café.

\section{Descripción del método}

Este trabajo de investigación se realizó en base al análisis de tres diferentes tipos de suelos seleccionados de acuerdo con la altitud que se encuentran, fueron tomadas para estudio muestras de 600 a 800 metros sobre el nivel del mar (m.s.n.m.), de 1000 a 1200 m.s.n.m. y de 1600 a 1800 m.s.n.m. En los tres tipos de suelos se realizaron análisis fisicoquímicos; porcentaje de humedad, temperatura y $\mathrm{pH}$. Fueron tomadas 2 muestras de cada lugar, ya que variaba la altitud, se realizaron tres muestreos durante del periodo de Mayo-Julio de 2019.

\section{Muestreo del suelo para determinar la humedad y temperatura}

Para determinar las características físicas de la tierra se utilizó un prototipo Medidor de Temperatura y Humedad (METyHUM), el cual fue diseñado especialmente para este proyecto, es un artefacto capaz de medir la temperatura y humedad del ambiente como la humedad del mismo suelo.

LAGUNES-PAREDES, Yolanda, RAMÍREZ-ROMAN, Adolfo, SUAREZ-ALVAREZ, Ángel y OLIVARES-SILVA, Teresita de Jesús. Análisis de parámetros del cultivo y procesos de la transformación del café. Revista de Ingeniería Biomédica y Biotecnología. 2019 
Cuenta con programación basada en $\mathrm{C}++$ y dos placas con nombre Arduino las cuales servirán como interpretador de las señales que este recibe de los módulos te temperatura y humedad.

\section{Determinación de pH del suelo}

Se pesaron las muestras del suelo obtenidas de cada región, se colocaron en un vaso de precipitado de $250 \mathrm{ml}$, y en una balanza granataria digital se pesó $10 \mathrm{~g}$ de cada muestra, en total fueron 6 muestras, 2 por cada región. Posteriormente se agregaron $100 \mathrm{ml}$ de agua destilada a cada muestra y se agitó dejando reposar durante $10 \mathrm{~min}$.

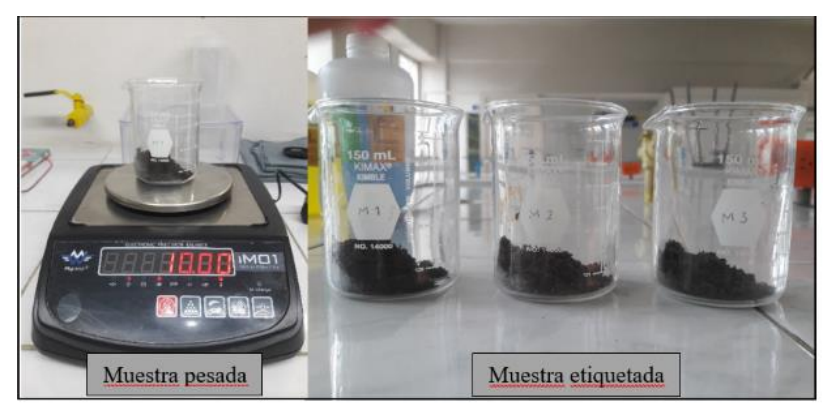

Figura 4 Muestras pesadas y etiquetadas, una por cada región

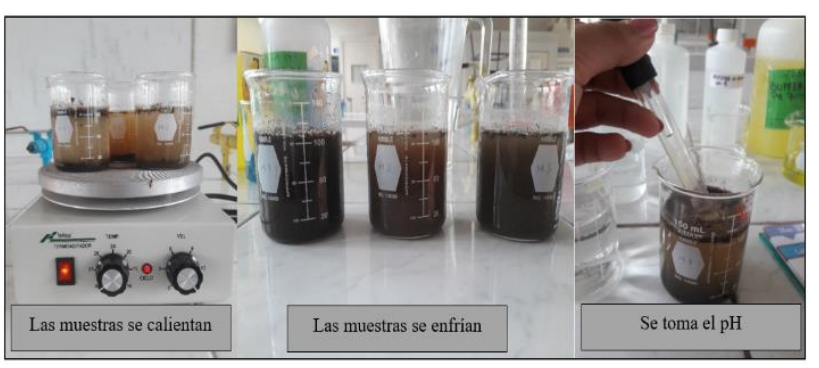

Figura 5 Calibración de potenciómetro, y análisis de cada una de las muestras

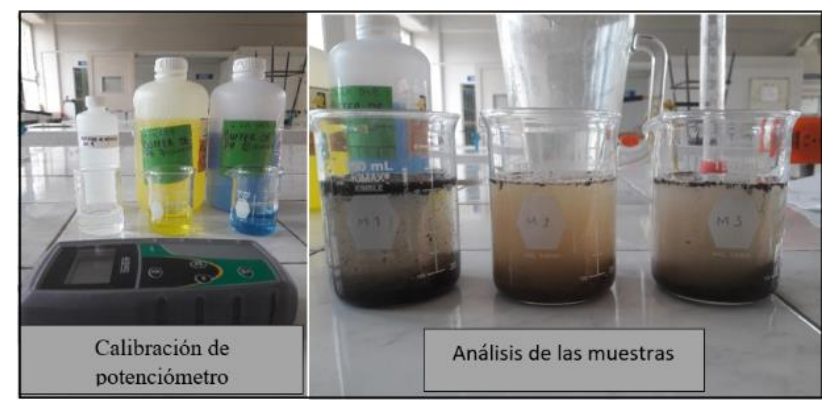

Figura 6 Las muestras se calientan, posteriormente se enfrían y se agitan y se toma el $\mathrm{Ph}$

Se ajustó el potenciómetro con las soluciones amortiguadoras; las cuales fueron soluciones Buffer de pH4, pH7 y pH10, una vez calibrado el potenciómetro se procedió a medir el pH.
Una vez habiendo obtenido un $\mathrm{pH}$ de cada una de las muestras, se procedió a calentar cada muestra en una parrilla, y dejarlas en punto de ebullición por 3 minutos. Se agitaron y se dejaron enfriar por $10 \mathrm{~min}$, y se volvió a tomar el $\mathrm{pH}$ con potenciómetro; el cual tuvo una pequeña pero significativa variación en cada una de las pruebas.

\section{Determinación de porcentaje de humedad del café verde u oro}

Para obtener el porcentaje de humedad del grano verde se utilizó una termobalanza. En primer lugar, se calibró la balanza, y posteriormente se colocó 1 gr de café verde y se procedió a calentar a $80^{\circ} \mathrm{C}$, se fue midiendo la cantidad de humedad y peso perdido cada $5 \mathrm{~min}$, para así lograr hacer un diferencial de tiempo vs humedad. En total fueron de 5 a 6 horas midiendo el porcentaje de humedad perdida del grano. Esto se hizo para el café verde de Córdoba (R1), Coatepec (R2) y Xico (R3).

La Organización Internacional del Café dice que los granos de café verde secos deben tener un contenido de humedad de $8 \%$ a $12,5 \%$, con la excepción de los "cafés de especialidad que tradicionalmente tienen un alto contenido de humedad.

Los buenos niveles de contenido de humedad permiten altas puntuaciones en catación, acidez equilibrada y un gran aroma. Hay un debate sobre cuál es el mejor nivel de humedad, pero $10 \%-12 \%$ es aceptado generalmente.

\section{Proceso de tostado}

Uno de los objetivos de este proyecto es determinar el grado de acidez del café tostado, para esto se consiguió café verde de cada región muestreada. Se hizo un proceso de tostado donde se obtuvo un término claro, medio y expresso, el tostado se realizó en el Laboratorio de Ingeniería Industrial Figura 6. Un tostador puede desarrollar estilos de tostado específicos para destacar los atributos de una variedad o región productora particular. Para este proyecto en específico se hicieron diversas visitas a industrias de beneficio de café, en las cuales explicaron los diferentes tipos de secado; el beneficio seco y húmedo. Así como también el proceso de tostado, aunado a esto se estuvieron haciendo prácticas de tostado en Laboratorio de Ingeniería Industrial.

LAGUNES-PAREDES, Yolanda, RAMÍREZ-ROMAN, Adolfo, SUAREZ-ALVAREZ, Ángel y OLIVARES-SILVA, Teresita de Jesús. Análisis de parámetros del cultivo y procesos de la transformación del café. Revista de Ingeniería Biomédica y Biotecnología. 2019 
Con esta mediana experiencia con el tostado de café, se logró tostar un término claro, medio y expresso, del café de Córdoba (R1), Coatepec (R2) y Xico (R3).

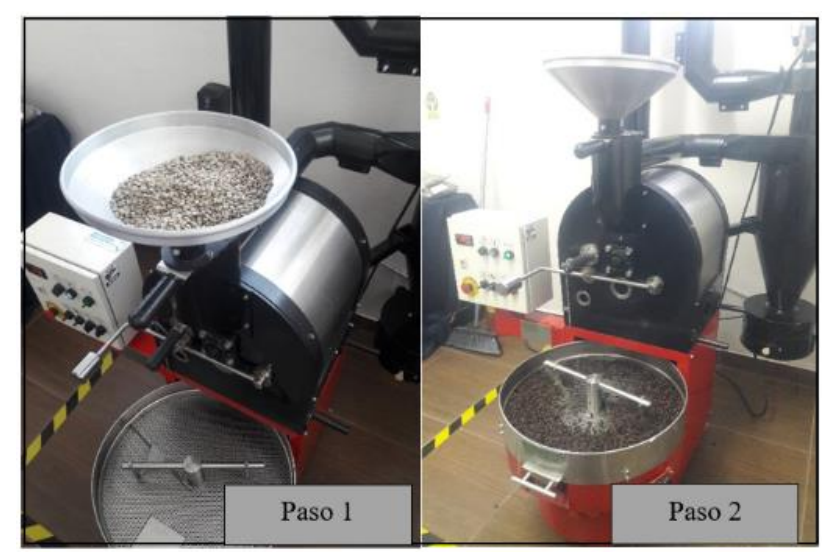

Figura 7 Proceso de tostado de café

Una vez obtenidos los tres términos de tostado de las tres diferentes regiones, se procedió a tostar el café en el Laboratorio de Ingeniería Industrial $\mathrm{F}$, el molino cuenta con nivel del 1 al 10, se molió en el nivel 4.

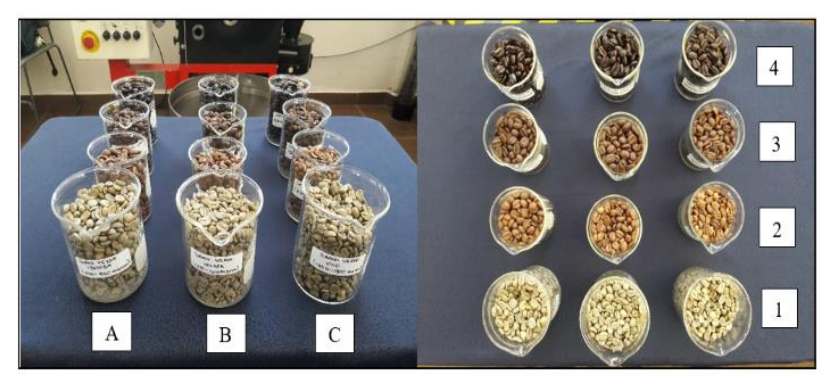

Figura 8. Café verde (1) y tostado en término claro (2), medio (3) y expresso (4), de Córdoba (A), Coatepec (B) y Xico (C).

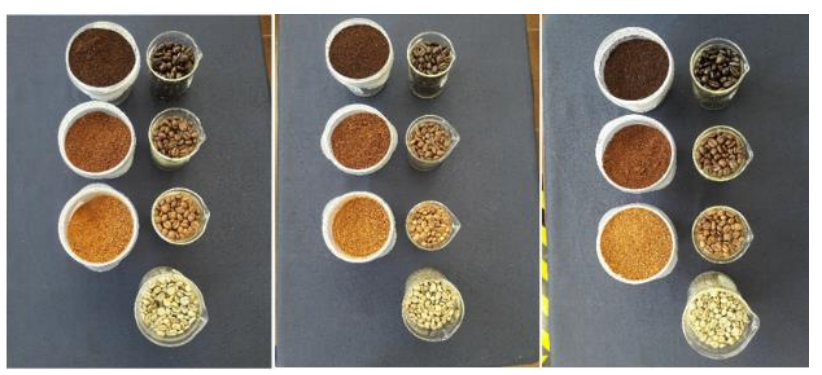

Figura 9. Café verde, tostado y molido de la región de Córdoba (R1), Coatepec (R2) y Xico (R3).

\section{Determinación de pH del café tostado}

Como último objetivo de este proyecto se debe determinar el grado de acidez del café tostado, para hacerlo de una manera química, se determinará con un potenciómetro, esto únicamente para conocer el $\mathrm{pH}$.
Sin embargo, la taza de café está llena de complejidad, no solo es conocer el grado de acidez, también está el aroma, sabor y cuerpo; son factores que determinan la calidad del café. Pero aquí entra una técnica que es la catación, que solo se logra con la experiencia y dedicación.

Para catar un café se tiene que diluir 10 gr. de café en $200 \mathrm{ml}$. de agua, en este caso para obtener el $\mathrm{pH}$ se pesaron 5 gr. de café molido, en $100 \mathrm{ml}$. de agua destilada, esto se hizo con los tres términos de café de cada región, Córdoba (R1), Coatepec (R2) y Xico (R3). Las muestras se colocaron en un vaso de precipitado de $150 \mathrm{ml}$ y se etiquetaron. Posteriormente se calibró el potenciómetro con las soluciones Buffer de $\mathrm{pH} 4$, pH7 Y pH10. Se calentó 1Lt de agua pura, y se dejó hasta su punto de ebullición, se esperaron 3 min. y se agregaron los $100 \mathrm{ml}$ a cada muestra de café. Se dejó reposar 10 min y se procedió a tomar la muestra de $\mathrm{pH}$.

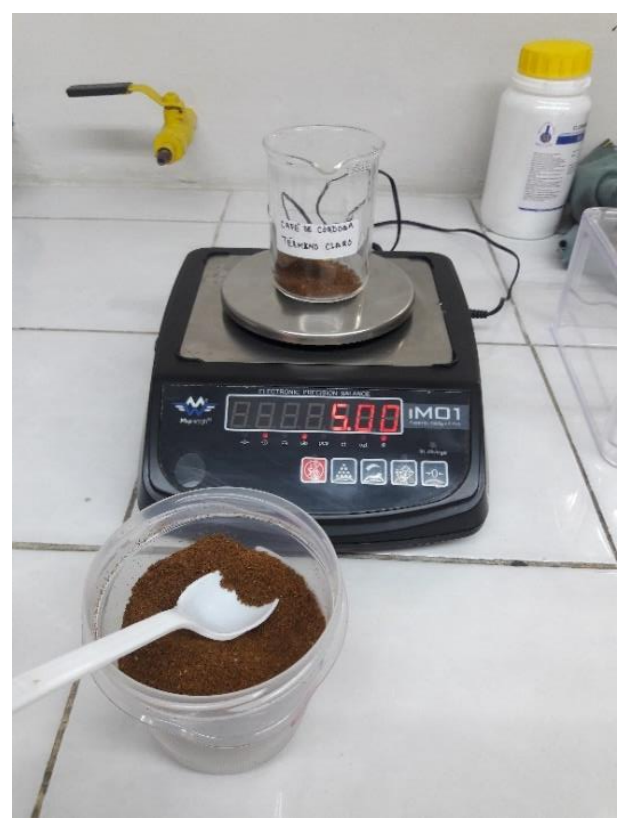

Figura 10 Muestra de 5 gr de café molido, pesado en la balanza analítica

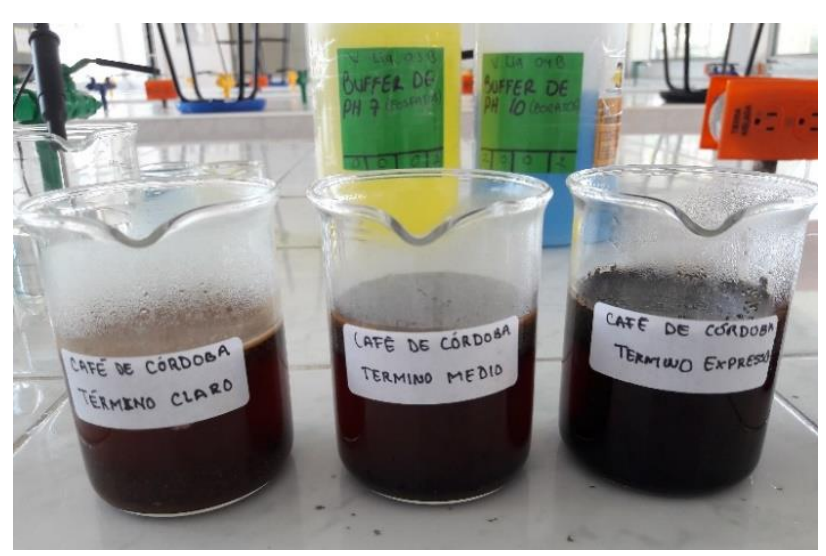

Figura 11 Muestras de los tres términos del café tostado y diluido de Córdoba (R1)

LAGUNES-PAREDES, Yolanda, RAMÍREZ-ROMAN, Adolfo, SUAREZ-ALVAREZ, Ángel y OLIVARES-SILVA, Teresita de Jesús. Análisis de parámetros del cultivo y procesos de la transformación del café. Revista de Ingeniería Biomédica y Biotecnología. 2019 


\section{Resultados}

\section{Comparación de temperatura de las tres regiones:}

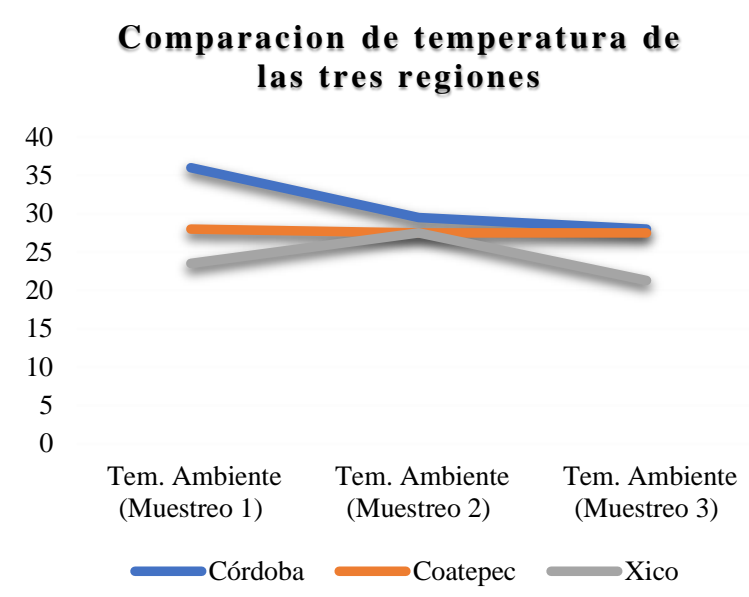

Gráfico 1 Comparación de temperatura de las tres regiones

Datos de porcentaje de humedad del suelo de las tres regiones:

Humedad del suelo de la R1

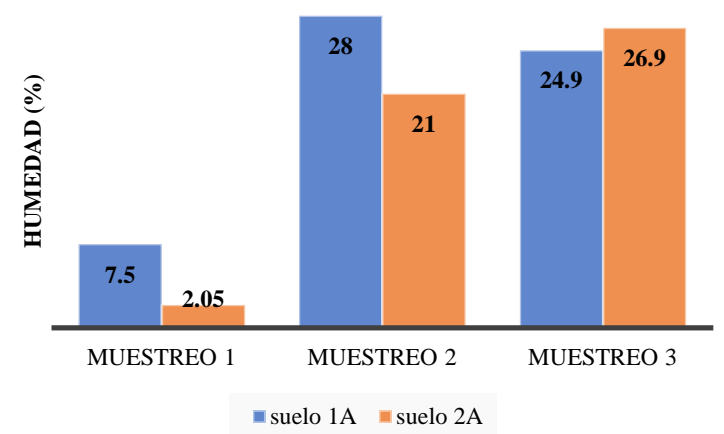

Gráfico 2 Porcentaje de humedad del ambiente de la región de Córdoba (R1)

\section{Humedad del suelo de la R2}

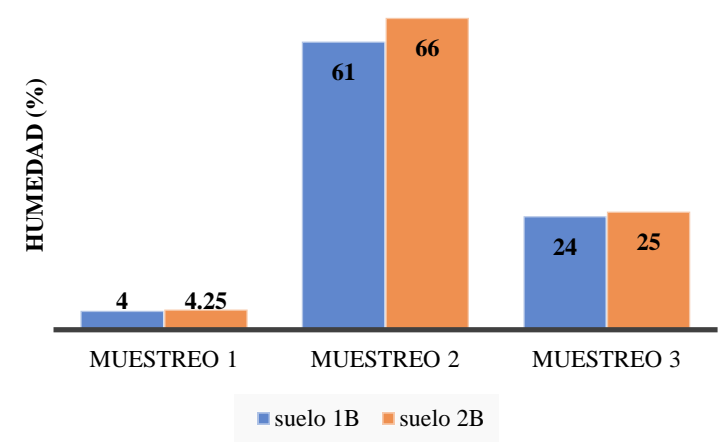

Gráfico 3 Porcentaje de humedad del ambiente de la región de Coatepec (R2)
Humedad del suelo de la $\mathrm{R3}$

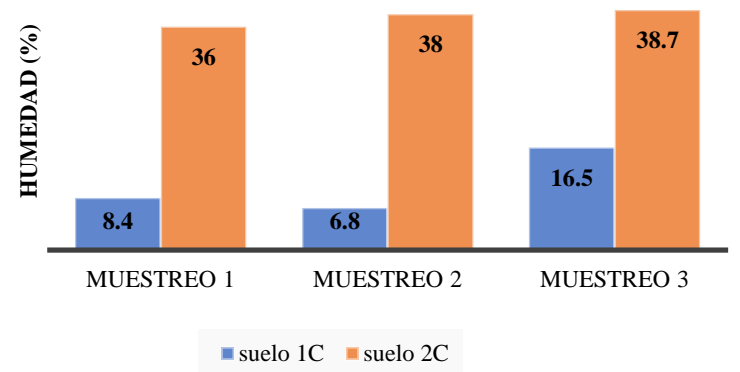

Gráfico 4 Porcentaje de humedad del ambiente de la región de Xico (R3)

Datos de porcentaje de humedad del suelo de las tres regiones:

Humedad del suelo de la R1

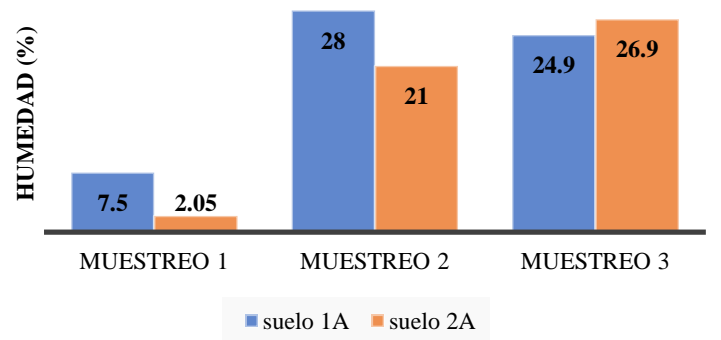

Gráfico 5 Humedad del suelo de la región de Córdoba (R1)

\section{Humedad del suelo de la R2}

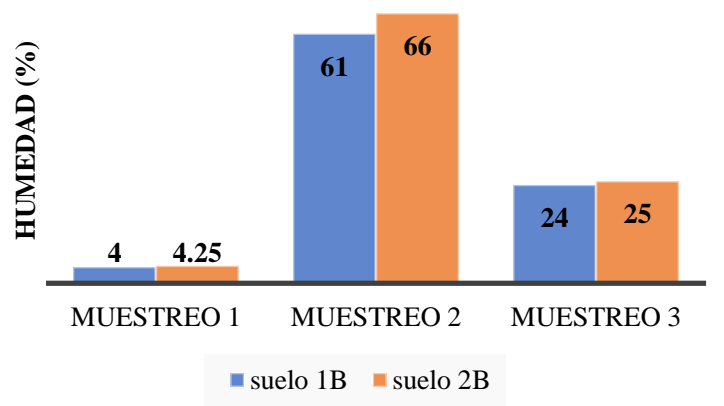

Gráfico 6 Humedad del suelo de la región de Coatepec (R2)

Humedad del suelo de la $\mathbf{R 3}$

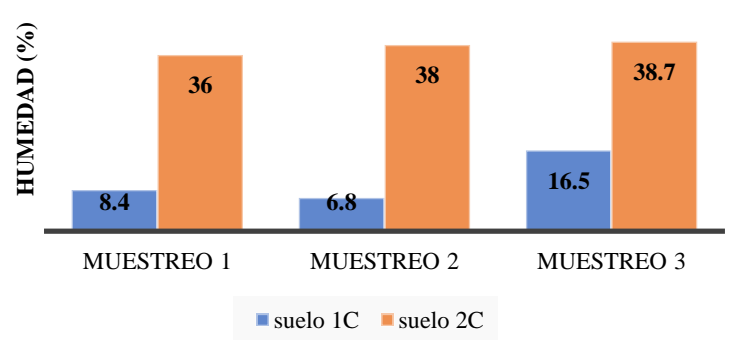

Gráfico 7 Humedad del suelo de la región de Xico (R3)

LAGUNES-PAREDES, Yolanda, RAMÍREZ-ROMAN, Adolfo, SUAREZ-ALVAREZ, Ángel y OLIVARES-SILVA, Teresita de Jesús. Análisis de parámetros del cultivo y procesos de la transformación del café. Revista de Ingeniería Biomédica y Biotecnología. 2019 
pH de suelo 1A y suelo 2A de la R1

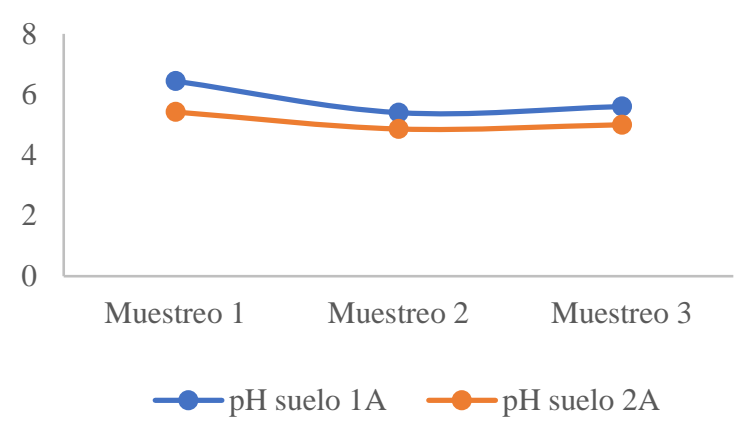

Gráfico 8 Comparación del pH del suelo 1A y suelo 2A de la R1

pH de suelo 1B y suelo 2B de la R2

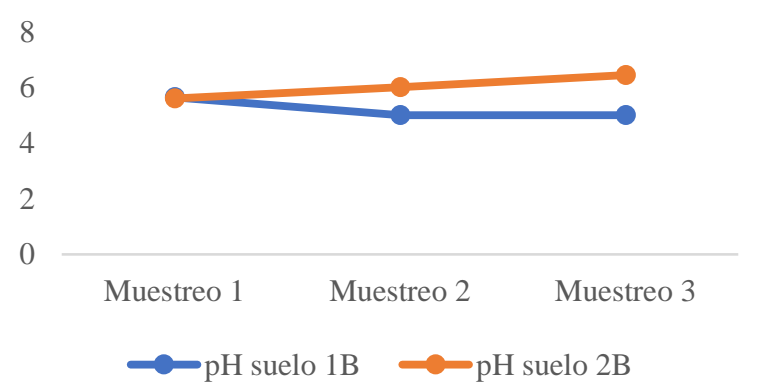

Gráfico 9 Comparación del pH del suelo 1B y suelo 2B de la R2

pH de suelo 1C y suelo 2C de la R3

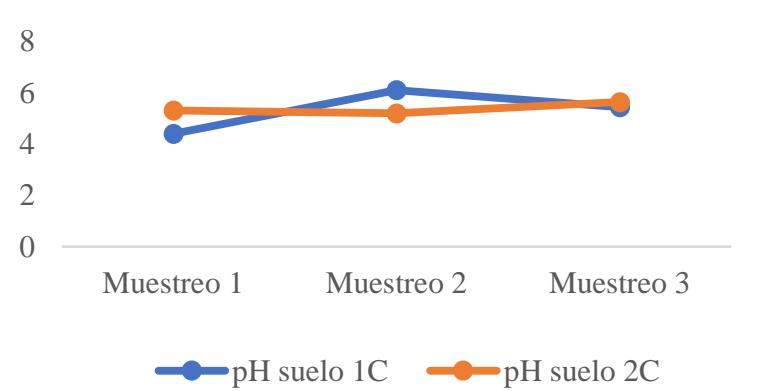

Gráfico 10 Comparación de pH del suelo 1C y el suelo 2C de la R3

\section{Porcentaje de humedad del café verde u oro}

El primero en determinar fue el café verde de Xico (R3), se pesaron 1.002 gr de grano, y se dispusieron a secar en la termobalanza a $70^{\circ} \mathrm{C}$. El proceso de secado tardó 5 horas 25 minutos. Quedando con un porcentaje de humedad total perdido de $11.4 \%$. El segundo en determinar fue el café verde de Córdoba (R1), se pesaron 1.001 gr de grano, y se dispusieron a secar en la termobalanza a $80^{\circ} \mathrm{C}$. El proceso de secado tardó 5 horas 30 minutos. Quedando con un porcentaje de humedad total perdido de $10 \%$.
El tercero en determinar fue el café verde de Coatepec (R2), se pesaron 1.003 gr de grano, y se dispusieron a secar en la termobalanza a $85^{\circ} \mathrm{C}$. El proceso de secado tardó 3 horas 30 minutos. Quedando con un porcentaje de humedad total de $10.7 \%$.

\section{Porcentaje de humedad del café verde}

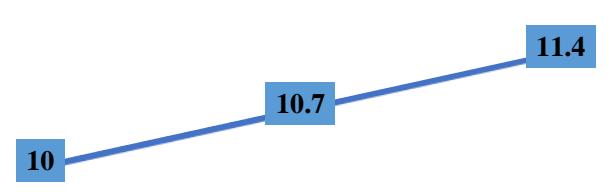

Córdoba (región 1) Coatepec (región 2) Xico (región 3)

Gráfico 11 Porcentaje de humedad del café verde

\section{El tostado del café}

A continuación, se presentan las curvas de tostado de café de Córdoba, Coatepec y Xico.

Curva de tostado del café de la R1

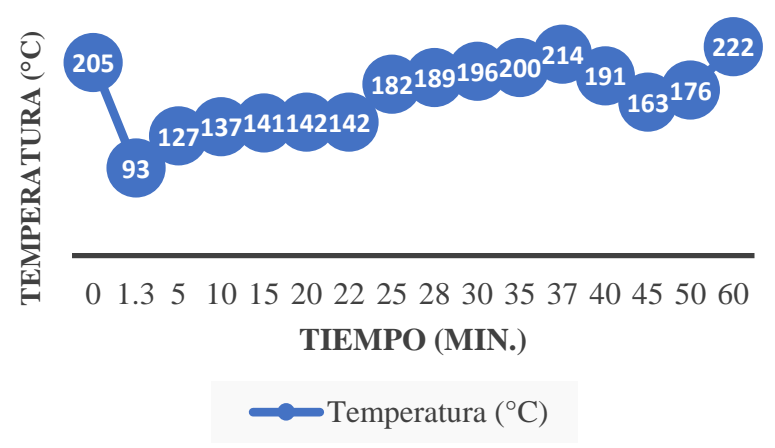

Gráfico 12 Curva de tostado del café de Córdoba (R1)

Curva de tostado del café de la $\mathbf{R 2}$

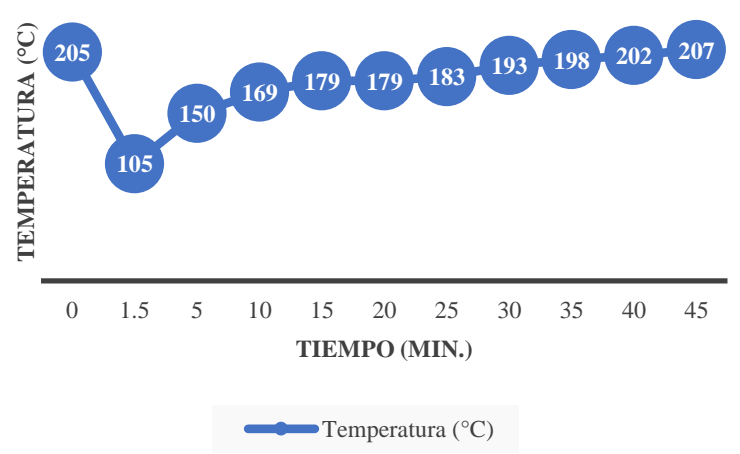

Gráfico 13 Curva de tostado del café de Coatepec (R2) 


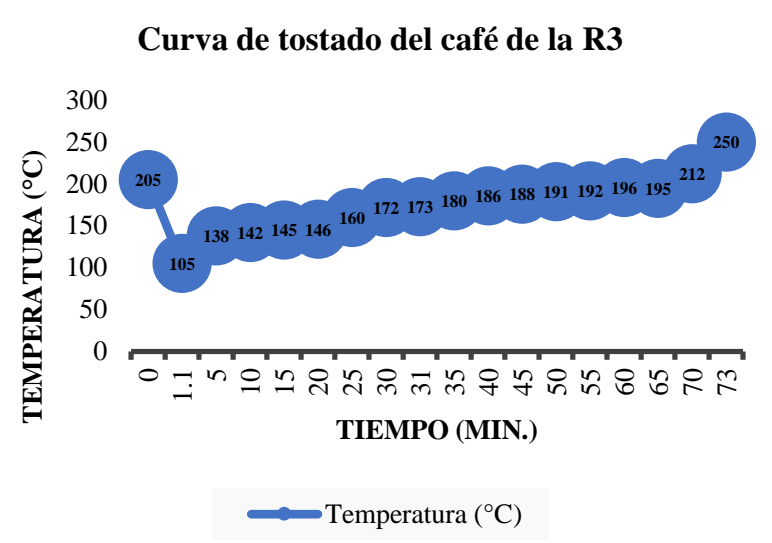

Gráfico 14 Curva de tostado del café de Xico (R3)

\section{pH del café diluido}

\begin{tabular}{|l|c|r|r|}
\hline \multicolumn{4}{|c|}{ pH de café diluido } \\
\hline Región & $\begin{array}{c}\text { Término } \\
\text { claro }\end{array}$ & $\begin{array}{c}\text { Término } \\
\text { medio }\end{array}$ & $\begin{array}{c}\text { Término } \\
\text { expresso }\end{array}$ \\
\hline Córdoba (R1) & 5.01 & 5.6 & 5.84 \\
\hline Coatepec (R2) & 5.06 & 5.52 & 6.1 \\
\hline Xico (R3) & 5.46 & 5.84 & 6.06 \\
\hline
\end{tabular}

Tabla 2 pH de café diluido de las tres regiones

\section{Agradecimientos}

Este trabajo de investigación forma parte de los productos derivados del proyecto de investigación: Análisis de las operaciones de la transformación del grano de café. Así mismo es financiado por PRODEP del Cuerpo Académico UV-CA-470 Innovación en Sistemas de Gestión, mediante oficio de autorización DSA/511-6/188329

\section{Conclusiones}

En base a los resultados obtenidos durante el desarrollo de este proyecto de investigación se puede concluir que:

- $\quad$ Altitud repercute en la temperatura: En cuanto más altitud tenga una región (1200-1700 m.s.n.m.), la temperatura disminuye, en este caso de las tres regiones muestreadas, la región de Xico (R3) fue la de mayor altitud y la que presentó menor temperatura ambiental, y la región de Córdoba (R1) la de menor altitud, presentó mayor temperatura ambiental, y la región de Coatepec (R2) con una altitud y temperatura por en medio de las otras regiones.
La humedad depende de la temperatura: La temperatura de las tres regiones disminuyó muestreo con muestreo lo cual repercutió en la humedad del ambiente, ya que esta fue muy poca en las tres regiones y aumentó considerablemente de la muestra 1 a la muestra 3 , la región de Córdoba ( $\mathrm{R} 1)$ disminuyó de $36^{\circ} \mathrm{C}$ a $27.5^{\circ} \mathrm{C}$, la región de Coatepec (R2) disminuyó de $28^{\circ} \mathrm{C}$ a tan solo $27^{\circ} \mathrm{C}$, la región de Xico (R3) disminuyó de $23.5^{\circ} \mathrm{C}$ a $21.3^{\circ} \mathrm{C}$, por consiguiente:

- La humedad repercute en la acidez del suelo: Concluyendo, las zonas con mayor precipitación total anual que va de los $750 \mathrm{~mm}$ anuales (7.500 $\left.\mathrm{m}^{3} / \mathrm{ha}\right)$ hasta $3000 \mathrm{~mm}\left(30.000 \mathrm{~m}^{3} / \mathrm{ha}\right)$ y por ende mayor humedad presentan en el suelo una acidez mucho más marcada que las zonas menos húmedas. En este caso el suelo de la región de Xico presentó una mayor acidez que la región de Coatepec y Córdoba.

- $\quad$ La acidez del suelo repercute en la acidez del café tostado: El pH del suelo de Córdoba presentó una mayor acidez que las otras dos regiones, sin embargo, en el café tostado si presentó una acidez muy marcada. El pH del suelo de Coatepec se puede considerar en partes casi neutro, y su tostado presentó una acidez no tan marcada.

El pH del suelo de Xico presentó una acidez muy alta, sin embargo, el café tostado indicó una acidez baja, se podría decir que fue el café menos ácido de las tres regiones.

Haciendo una conclusión en base a estos resultados se puede decir que la acidez del suelo es inversamente proporcional a la acidez del café tostado.

\section{Referencias}

Benegas Romero. (2009). Identificación de las fuentes de variación que tienen efectos sobre la calidad del café (Coffea Arábica) en los municipios de el Paraiso y Alauca, Honduras (Tesis).

http://orton.catie.ac.cr/repdoc/A3072E.PDF

Guillermo Canet Brenes, C. S. (2016). La Situación y tendencias de la producción de café en América Latina y El Caribe por IICA. Estado de Jalisco A.C.: Jorge Valente García.

Organización Internacional del Café. http://www.ico.org

LAGUNES-PAREDES, Yolanda, RAMÍREZ-ROMAN, Adolfo, SUAREZ-ALVAREZ, Ángel y OLIVARES-SILVA, Teresita de Jesús. Análisis de parámetros del cultivo y procesos de la transformación del café. Revista de Ingeniería Biomédica y Biotecnología. 2019 
Ramirez Ovalle. (2009). Evaluación del rendimiento de extracción y caracterización del aceite fijo de café tostado tipo genuino antigua obtenido por el proceso de prensado (Tesis). http://biblioteca.usac.edu.gt/tesis/08/08_1093_ Q.pdf

Rosales, C. H. (2018). Café de Veracruz, el de mayor calidad en el país. Universo, sistema de noticias de la UV.

Zambrano Flores. (2014). Determinar la calidad de granos de selecciones avanzadas de café robusta (Coffea canephora) (Tesis). (http://repositorio.educacionsuperior.gob.ec/bits tream/28000/3464/1/tesis\%20cafe\%20Fanny\% 20Zambrano.pdf 